\title{
DEUS E O DIABO NUMA TERRA EM BUSCA DO SOL
}

Robson Dutra

(Unigranrio)

\section{RESUMO}

Este texto tem como objetivo refletir sobre O Sétimo juramento, de Paulina Chiziane, e as configurações estéticas, históricas e sociais ali presentes a partir da polarização ente bem e mal, passado e presente, colonialismo e pós-colonialismo, de modo a buscar respostas a algumas indagações da Moçambique contemporânea. Assim, entre sombras e abismo, segredos e magias, pretendemos considerar o legado histórico-cultural deste país, suas tradições e seu devir.

PALAVRAS-CHAVE: Moçambique; ruptura; Pós-colonialismo.

\section{ABSTRACT}

The aim of this text is to reflect about O Sétimo juramento, by Paulina Chiziane, and some aesthetic, historical and social issues that are considered upon polarization between good and evil; past and present, colonialism and post-colonialism, in order to search answer some questions contemporaneous Mozambic has been asking. Therefore, from shadows and abyss, secrets and magic on, we consider Mozambican historical and social legacy, her tradition and becoming.

KEYWORDS: Mozambic; rupture; Post Colonialism. 
Um dos traços que melhor caracteriza os estudos pós-coloniais é a transversalidade que une diversos campos do saber, de modo que a Literatura, a História, a Antropologia e a Ciência Política, por exemplo, são requisitadas a uma análise pormenorizada das diversas maneiras pelas quais a pós-modernidade pode ser compreendida e analisada. A partir daí, podemos estudar algumas facetas do colonialismo, bem como o rumo das antigas colônias em épocas posteriores ao processo de contestação e libertação deste sistema de governo.

Todavia, não há consenso em torno das categorias envolvidas ou do próprio significado do termo "pós-colonial". Ao contrário, o que se percebe como ponto comum é que as muitas referências à terminologia e às problematizações decorrentes de suas investigações surgiram, primeiramente, entre teóricos anglo-saxônicos para, posteriormente, difundirem-se entre intelectuais da diáspora do colonialismo francês e, mais recentemente, do português e do espanhol, fator que amplia a semântica dos "estudos pós-coloniais", bem como suas especificidades.

Com efeito, este período tem sido pensado através de três diferentes perspectivas não necessariamente contraditórias entre si, como a que considera o pós-colonial como uma teoria; a que o define como uma situação global contemporânea e, por fim, a que denomina como tal a condição política dos Estados nacionais após o processo de independência de suas antigas colônias, concepção com a qual, por sinal, este artigo dialoga mais intensamente. Entretanto, estas diferentes visões abarcam algumas similaridades, como as muitas interrogações que se faz à História e ao processo identitário das nações envolvidas, bem como aos rumos a serem tomados tanto pelas antigas metrópoles, quanto as ex-colônias.

Desse modo, é possível afirmar que, em África, uma de suas marcas mais acentuadas é a tentativa de superação da crise produzida pela inabilidade de compreensão do mundo através de procedimentos que deslocam e repensam o conhecimento oriundo da dominação ocidental/ colonial. Com isso, busca-se redimensionar a relação entre colonizador e colonizado através do surgimento de uma fronteira, de um entrelugar em que novos sentidos são negociados.

Ao reduzir o imaginário do colonizado, a política "civilizatória" operou uma transfiguração do tempo passado, fator que o destituiu de sua memória cultural através de um longo e doloroso processo de coisificação que resultou, por exemplo, num sentimento de inferioridade crucial aos propósitos da dominação. Deu-se, portanto, um desvirtuamento cultural adquirido à custa de um falseamento da História, da qual, por muito tempo, o colonizado se viu tolhido. Esta é a perspectiva de Berque ao cunhar o termo "desnaturação" para referir-se a este processo, uma vez que 
o livre desenvolvimento das civilizações extra-européias, sendo a colonização, antes de mais nada, uma obra de desnaturação: freia a natureza do outro para explorálo; suplantá-lo em todos os campos - político, artístico, lingüístico - e joga sobre o outro uma opacidade que contribui para obscurecê-lo. Ele é cortado de sua história, amputado de sua herança [...] e deve reconstruir sua personalidade em função do modelo imposto pelo dominador. (BERQUE apud FERRO, 1996, p. 213)

Sendo assim, será apenas após a purgação de antigos traumas que esta nova estrutura poderá ser absorvida, "descrevendo uma consciência pós-colonial” (WILLIAMS, 1987, p. 19), cuja via principal de expressão tem sido a escrita literária. É, portanto, através dela que antigas questões afloram em busca de uma nova sintonia com uma percepção de viés histórico-cultural que, no todo, entretanto, ultrapassa os limites da literatura, numa clara opção discursivo-ideológica dos escritores.

Soma-se a isso o processo da pós-modernidade que, apesar de igualmente amplo, tem como princípio comum o fato de que o pós-moderno é a extensão da modernidade em que os estudos pós-coloniais despontaram, englobando-a a fim de cobrir o desenvolvimento do mundo diante da queda das ideologias do século XX.

Esta parece ser a intenção subjacente a O Sétimo juramento, romance de autoria de Paulina Chiziane (2000), cujo eixo temático gira em torno de um sistema de oposições e dualidades que parodiam algumas das representações inerentes ao colonialismo. Em comum com Ventos do Apocalipse (1991), Balada de amor ao vento (1995) e Niketche (2002), este romance traz à cena o quotidiano feminino, revelando os meandros que determinam a vida da mulher, mesmo numa sociedade urbana em que elas parecem conhecer maneiras diversas de driblar o peso da sua condição subalterna. Ao contrário dos demais, em O Sétimo juramento todas as personagens femininas residem em zonas urbanas e pertencem a uma burguesia que oscila em torno do poder político-social ao qual a escritora dirige seu olhar aguçado, desmascarando comportamentos e atitudes.

Para além disso, entre encantamentos, maldições, vinganças e uma série de polarizações entre o bem e o mal, Chiziane também revela a dimensão humana de seu povo, entremeada por costumes ancestrais e que, diante do hibridismo resultante da dominação imperialista, faz com que a sociedade conviva com filosofias de vida bem diversas. Reconstruindo esses lugares de medo e de esperança, Paulina nos oferece uma visão própria, com um matiz singular de personagens que vivem num clima marcado pela dimensão mágica e alegórica da feitiçaria. É a partir do maniqueísmo que opõe claramente o bem ao mal, o passado ao presente, as tradições à modernidade, que a escritora viabiliza o questionamento da História e da própria condição pós-moderna através desse entrelugar proposto pela 
literatura e os novos sentidos dele resultantes. Por isso, desde o primeiro capítulo, "mulher e homem, forte e fraco, fogo e água, desfilam em círculo como as estações do ano" (CHIZIANE, 2000, p. 11), integrando a natureza como um sistema por onde circulam, individualmente, elementos opositores que, todavia, compõem o todo universal.

Muito embora o romance seja posterior à revolução colonial e à guerrilha civil, que a sucedeu, a guerra é ainda tema recorrente através do qual a escritora volta os olhos ao passado a fim de narrar sua nação, sobressaltando o fato de que, no presente enunciado, a situação pós-colonial "construirá o majestoso palácio imperial com ossadas humanas que andam às toneladas nas matas". Dessa maneira revela um outro sistema de oposições a ser tematizado no romance, que é o meio urbano em oposição ao rural, bem como assinalando que a guerra do presente é que envolve o "pão e os direitos do homem" (CHIZIANE, 2002, p. 13).

É a partir desses meandros que a narrativa busca referenciar a memória dos atos de barbárie cometidos em/contra Moçambique, associando-os a aspectos comuns aos vários registros de violência da História. Pela busca da cosmogonia nacional, Paulina Chiziane relaciona, ainda no sistema gerador do bem e do mal, grupos étnicos moçambicamos, como ngunis e ndaus, às práticas que a narrativa encena a partir deste mesmo princípio. Todavia, tal maniqueísmo não se estende à construção das personagens, muito embora elas sejam apresentadas a partir das diferenças oriundas destas etnias, representando, lato sensu, heróis e vilões, sem, entretanto, interferir nas contradições internas de que são portadoras.

Sendo assim, o diálogo que se estabelece com a memória parte de uma visão extremamente matizada, não apenas de seu valor, mas de sua funcionalidade, ou seja, ela é fundamental para a construção e afirmação identitária, para a conscientização da relação entre as tragédias do passado e a tentativa de retomada dos rumos do presente, que também é justificado pela revisão da História. A semântica do trágico presente em O Sétimo juramento corresponde à concepção de Todorov (2002) ao examinar as diversas formas de rememorar o passado. Por isso, a tragédia ali referida não significa apenas sofrimento, dor ou aflição, mas a impossibilidade de o bem ser atingido, pois qualquer que seja o desenlace escolhido, ela será sempre fautora de lágrimas e morte.

É esta polarização que é encenada no romance a partir da trajetória de Davi, um ex-guerrilheiro que, após o êxodo dos antigos colonos e o sistema de benesses oriundo do novo governo, torna-se presidente de uma estatal. Todavia, fazendo valer a premissa de que "mudam-se os tempos, mudam-se as vontades", o discurso utópico se esvai ao longo da trajetória da personagem, visto que os lucros da empresa tornam-se a forma encontrada para o enriquecimento às custas de desvios de verbas e outras ilicitudes perpetradas contra a empresa e seus operários, o que resulta no atraso do pagamento e na eclosão de greves. Ou seja, apesar da tentativa 
de forjamento do "homem novo" pós-colonial, bem como a "inquisição revolucionária" empregada nesta empreitada (CHIZIANE, 2000, p. 46), o que se lê é a perpetuação dos mesmos elementos coercivos usados pelo colonialismo na manunteção do status quo. Por isso, como enuncia um dos operários grevistas, alguns deles ex-revolucionários (CHIZIANE, 2000, p. 114), "antes a liberdade era boa. Lutar contra o colonialismo e a liberdade valia a pena. Hoje não dá gosto nenhum. É difícil lutar contra o novo potrão, porque é compatriota, irmão" (CHIZIANE, 2000, p. 212).

$\mathrm{Ou}$, como no confronto entre Davi e uma outra grevista:

- És negro - diz a mulher gorda. - Vieste do nosso ventre e amamos-te. Significavas para nós a geração de escravos que se libertou. Eras o nosso orgulhos. Com os teus olhos víamos o mundo que nos fora negado ao longo dos séculos. Quando viajavas para o estrangeiro, rezávamos por ti porque eras a nossa presença na história do mundo. Eras a cultura que sempre sonhamos ter, mas que a história nos negou. Abandonaste-nos. És tirano. (CHIZIANE, 2000, p. 69)

Diante da possível perda da posição social e dos privilégios adquiridos, Davi busca auxílio na magia negra através de Lourenço, um amigo do passado que o seduz com uma pretensa retomada da ancestralidade que o leva a comprometer-se com uma série de pactos e juramentos, entre os quais a imolação de seus companheiros, familiares e a violação da própria filha. Tais práticas ajudam-no a aumentar seu poder financeiro e sua capacidade de controle e explansão dos negócios, livrando-o de seus antagonistas, até perder, finalmente, o poder, ser acuado pelo povo, precipitando-se em queda e desgraça.

É interessante observar a simbologia dos nomes das personagens principais do romance, pois Davi remete à Bíblia, àquele jovem que não fraquejou diante do gigante Golias, a quem enfrentou e venceu, apesar da desvantagem física, sendo aclamado rei por sua sabedoria, coragem e determinação. A deturpação do caráter da personagem do romance é, possivelmente, uma forma de criticar a presença religiosa e europeia em Moçambique ao revelar os diferentes matizes culturais do povo diante da dominação ideológica da Igreja Católica e dos sistemas reducionistas empregados.

Semelhantemente, o radical do nome de sua esposa, Vera, aponta aquela que busca a verdade e que não fraqueja diante dos empecilhos que a fazem, por exemplo, vaguear pelo país em busca de respostas, indo contra o marido e as convenções sociais que reservam à esposa um lugar hierarquicamente inferior. Diferentemente de Cláudia e Mimi, secretária e amante de Davi, respectivamente, que se tornam, no entanto, futuras mães de seus filhos, e mesmo tia Lúcia, a cafetina que oferece a jovem prostituta a Davi, Vera não mede esforços para defrontar-se com a verdade que assegurará a tranquilidade de sua família. Assim, esta crítica tanto pode ser 
direcionada à cultura ocidental como à do próprio país, que ainda se vale do lobolo, ou seja, o dote de casamento, bem como de tabus como o da virgindade e o da poligamia.

Clemente, por fim, é o filho que, apesar de vitimado pela desagregação familiar, opta pelo perdão e pela clemência diante dos desmandos do pai, buscando na tradição e na magia branca desarticular a insensatez que resultou na ambição que tragou Davi e, alegoricamente, o corpo da nação. É o jovem, cujas visões e pesadelos foram inicialmente interpretados como problemas mentais, que combate e vence o pai ao fim de uma batalha que conduz Davi à morte, bem como ao colapso das forças que este representa. Tal se dá após a descobera de sua ligação com os espíritos ancestrais ngunis que, como representantes das forças do bem, o levam a abandonar a casa paterna a fim de se iniciar nos estudos de magia numa aprendizagem que se dá no fundo do mar (CHIZIANE, 2000, p. 251). Conhecendo, controlando seus poderes e habilitando-se a proteger sua família, o jovem vence, finalmente, o duelo contra as forças do mal.

Morte e destruição são, por sinal, o resultado final dessa narrativa que não nos permite caracterizar plenamente as personagens como heróis ou vilões, visto que estas são resultantes de uma série de conflitos seculares que devem ser considerados. Essa é a razão por que, diante de um adivinho, Davi ouve:

És a árvore de casca carnuda, tão amarga que ninguém morde. És canhi, fruto doce, perfumado. Bebida espirituosa, afrodisíaca, que faz o homem e a mulher unirem-se no prazer divino. És remédio e feitiço. És a árvores dos antepassados. Reúnes em ti poderes do bem e do mal. (CHIZIANE, 2000, p. 87)

Essas ambiguidades são percebidas ao longo da obra, de modo que, desde os primeiros capítulos, o embate entre passado e presente, bem como os confrontos contra o colonialismo, são fonte de atribulação para Davi, que

vai à janela e espreita o sol. A madrugada está chuvosa e triste. $\mathrm{O}$ vento arrasta nuvens densas que trazem à alma medos inimagináveis. Pensamentos maus transbordam como uma fonte de águas turvas. O corpo gordo fica abatido em segundos. (CHIZIANE, 2000, p. 14)

Da lembrança do passado e da revolução surge a convicção de que "naquele tempo tinha o coração do tamanho do povo. Agora a palavra povo é um simples número, sem idade nem sexo (...), apenas estatística” (CHIZIANE, 2000, p. 14). Contudo, não obstante o aparente desconforto, a lembrança dos antigos dias como guerrilheiro cessa e o passado, aparentemente, deixa de assombrá-lo, fazendo com que, paulatinamente, a personagem encontre justificativas para as incoerências do presente: 
Estes operários rebelaram-se contra a administração colonial. Hoje, rebelam-se contra os libertadores da pátria, ingratidão típica dos filhos de Israel. O povo é vento que corre para qualquer lado (...) Dez anos durou a luta de independência para libertar a terra. Hoje, o país tem sua identidade, liberdade, estatuto. Alguns operários chegam a afirmar que a vida era melhor no tempo dos colonos. Mas a culpa maior cabe a nós, militantes da utopia, que prometemos um mundo pleno de igualdade. De onde fomos buscar semelhante loucura, se a igualdade não existe nem no reino das formigas? (CHIZIANE, 2000, p. 32-33)

Esta tensão temporal também afeta Vera, que se une a Clemente na anulação aos males provocados por Davi. Por essa razão, a ida inicial a um adivinho, nos arredores da cidade, mas que se mostra incapacitado a ajudá-la, dada a dimensão da magia envolvida, os leva cada vez mais para fora dos limites da cidade, aos recônditos de Moçambique, "aos montes que protegem o amor e castigam o ódio", dando "de comer a quem tem fome" (CHIZIANE, 2000, p. 221). Interessante é observar que Davi também empreende semelhante jornada, acompanhado de Lourenço. É no interior do país, num cenário em que "só a guerra governa", entre "abutres, cães vadios, cadáveres em putrefação e cápsulas de balas espalhadas pelo chão" (CHIZIANE, 2000, p. 135), que se dá o encontro de Davi com o insólito que a magia negra representa. Em "Massinga, a terra dos grandes mágicos" (CHIZIANE, 2002, p. 136), em meio à densidão da noite, num percurso em que o tempo mítico funde-se ao histórico (CHIZIANE, 2002, p. 107), Davi contempla a fortuna da família de Lourenço que, todavia, só pode ser vislumbrada durante o dia. À noite, espíritos considerados fracos, escravizados pelos mais fortes, trabalham para que o fausto possa ser contemplado pela manhã, num igual jogo de submissão. Ali, no campo abandonado pela elite obcecada pelas luzes da cidade (CHIZIANE, 2000, p. 136), reside o espírito de Makhulu Mamba, "personagem das lendas de terror do universo mítico dos tsongas" (CHIZIANE, 2000, p. 139), que, para garantir a fortuna de Lourenço, tomou da família as sete filhas virgens e impôs a rigidez horária. Metáfora do poder ndau que também garantirá a Davi o acúmulo de riquezas e prestígio, Mamba exige-lhe o sétimo juramento, o da feitiçaria, referido como "a escola dos governadores da vida" (CHIZIANE, 2000, p. 167). Este juramento será somado aos seis prestados anteriormente: do batismo, da bandeira, do matrimônio, da revolução, da nação, da competência e do zelo (CHIZIANE, 2000, p. 152), e terá como ônus o oferecimento de sua alma e de sua família, o que faz com que esta narrativa possa ser lida como uma versão moçambicana do Fausto, de Goethe.

Para Vera, no entanto, a viagem tem uma significação diferente da do marido porque rememorar o passado lhe traz a sensação incômoda de contraste com o presente, uma vez que a miséria da infância difere da opulência vivenciada agora, que, todavia, é apenas material. Interiormente, a personagem sente-se igualmente miserável, de modo que o retorno à ter- 
ra natal e às brincadeiras infantis lhe trazem o bem-estar de uma época de dificuldades, mas que, se comparada com sua vida atual, ressalta que nem sempre a ascensão social é a resposta para o conforto verdadeiro.

A polaridade entre o ontem e o hoje não apenas revela tais conflitos, como também acentua o abismo que se criou no presente em relação às tradições ancestrais. $\mathrm{O}$ distanciamento delas surge, frequentemente, como algo a ser lamentado, não significando, porém, que a cultura ancestral esteja livre de críticas. Diversas vezes, ao longo do texto, as tradições são criticadas e questionadas deliberadamente pela enunciação, evidenciando que não devem ser vistas como essencialmente boas ou más, como se pode depreender do fragmento abaixo:

A tradição bantu instrumentaliza o homem e faz dele combatente do nada. Trabalha duro e constrói. Na hora em que o infortúnio bate à porta e ele fecha os olhos para o todo e sempre, a família mais chegada, invocando a tradição, assalta-lhe e disputa os bens. (CHIZIANE, 2000, p. 37)

O presente, por sua vez, surge como uma reiteração do passado em mais de uma instância. Primeiramente, porque o comportamento de Davi e da elite moçambicana reduplicam o comportamento do colonizador, evidenciando o modo como a memória do mal cometido no outrora desencadeia e tenta justificar a violência do mal presente. Em outro aspecto, a ligação de Davi com a feitiçaria repete a história de sua própria família, visto que seu pai também sacrificou e violentou seus filhos e esposa em nome do poder.

Esta situação, todavia, não se limita à mera repetição de um trauma, pois Davi desconhece o ato realizado por seu pai. Sua busca pelas forças da magia negra liga-se, de fato, ao destino traçado por seus ancestrais, como uma maldição que se perpetua ad infinitum. Tal destino, ainda que aparentemente irrevogável, é questionado, pois muito embora sua mãe tenha aceitado o pacto feito no passado, recusa-se a perpetuá-lo, no presente, negando-se a acobertar os crimes do filho. Por isso decide apoiar Vera, vítima, no presente, dos mesmos males sofridos por ela:

Sou feiticeira por casamento. Pensava que já não era. Agarrei-me à Igreja como bóia de salvação... Ai, deuses, ai, mortos! Será que desta linhagem não escapará nenhuma geração? As dívidas são antigas, não foram feitas por eles... As promessas não cumpridas são dos antepassados e não destas crianças, coitadinhas. Por que os filhos têm que pagar pelos erros dos progenitores. (CHIZIANE, 2000, p. 196)

Como é comum ao imaginário cultural africano, a força do passado surge como um imenso poder respaldado pela voz dos mais velhos, de modo que é a sogra que anuncia a Vera que os destinos de Davi e de Clemente já haviam sido determinados. É através dela que se sabe que a troca de Davi -de seu nome banto por um ocidental - de nada valeria diante do 
desejo dos antepassados. Do mesmo modo, o destino de Clemente como salvador da família também já fora estabelecido independentemente de sua vontade. Todavia, a enunciação deixa claro que nada impede que pactos feitos no passado sejam rompidos por personagens dispostas a mudar a história e é esta a mensagem latente que o romance veicula.

Muito embora a memória ancestral seja determinante para o desfecho da narrativa, parece estar clara a noção de que o uso eficaz da memória implica não apenas reproduzir ou resgatar o passado, mas interrogá-lo sistematicamente. Como Todorov demonstra (2002, p. 47), qualquer um é livre para se recordar da forma que quiser, mas também não resta dúvida de que algumas utilizações da memória são mais nobres do que outras, uma vez que ela pode resultar numa função emancipadora do homem.

Ao adentrar os limites do sagrado e do profano e do bem e do mal, a narrativa revela o paradoxo e a ambivalência perceptíveis em Moçambique, que fazem com que a feitiçaria seja o meio de obtenção do poder, como no caso de Davi, mas também uma via eficaz para obtenção de conhecimento e de mostras de fraternidade, tal qual ocorre, por exemplo, com o cristianismo.

Em O Sétimo juramento, Paulina Chiziane faz um levantamento minucioso de seu país, mostrando-nos elementos antropológicos consistentes ao retratar, pelo insólito, rituais e práticas religiosas animistas, como sacrifícios, imolações, incorporações que nos fazem contemplar aspectos culturais desconhecidos que nos envolvem, uma vez que sua escrita polemiza o status quo ao denunciar algumas das contradições histórico-sociais.

A insolitude presente ao longo obra, como os rituais que envolvem Davi, Susy, as virgens, bem como levitações, visões e a convivência com animais selvagens, por exemplo, parte do princípio psicológico que garante a percepção do estético. Em outras palavras, a insolitude é, fundamentalmente, um modo de produzir no leitor uma inquietação física através de uma outra, de ordem intelectual, que se origina da dúvida sobre a exequibilidade do fato narrado e das diversas possibilidades de ele ser ou não interpretado. Tal sentimento é entendido aqui em uma acepção intratextual, ou seja, como um efeito discursivo elaborado pelo narrador a partir de um acontecimento de duplo referencial. Contudo, é preciso frisar que o tipo de enigma que se apresenta é aquele que estimula a descoberta; que aciona a atividade do leitor em vez de imobilizá-lo pelo medo que caracteriza, por exemplo, as histórias tradicionais de terror (DUTRA, 2008, p. 12).

Com efeito, a narrativa insólita produz imagens aparentemente irreais que estimulam no leitor a vontade de situar suas causas, possibilidades ou significações, além, de obviamente, indagar sobre sua existência irreverente e provocadora. Irlemar Chiampi, denominando tais imagens de "hipóteses", afirma que essas narrativas falam de mistérios que revelam o sentido de "tudo aquilo que a inteligência humana é incapaz de explicar ou compreender" (CHIAMPI, 1980, p. 52), uma vez que o insólito 
contenta-se em fabricar hipóteses falsas (o seu "possível" é improvável), em desdenhar a arbitrariedade da razão, em sacudir as convenções culturais, (...) as explicações impossíveis se constroem sobre o artifício lúdico do verossímil textual cujo projeto é evitar toda asserção, todo significado fixo, fazendo da falsidade o seu próprio objeto, o seu próprio móvil. (CHIAMPI, 1980, p. 54).

Assim, o romance esvazia-se de significados cristalizados, deixando a emoção diante de uma razão desmantelada por fatos que revelam outras linguagens e discursos que, por sua vez, indagam as personagens e o leitor subjetivo.

Tal premissa nos conduz mais uma vez à narrativa tradicional africana, cuja discursividade se faz também através de perguntas retóricas que constituem um modo dedutivo de narrar. Dessa maneira, os muitos questionamentos acabam por destituir a razão que "tem como eixo a noção empírica de mundo real e a opinião corrente que temos das leis da causalidade, do espaço e do tempo: os rios não invertem seus cursos, os mortos não retornam para atormentar os vivos, as paredes não se deixam atravessar" (CHIAMPI, 1980, p. 54).

Tomando em consideração que o vocábulo "palavra" significa "fala", "abertura", "instauração", "mito", e tendo em vista que a matéria prima da poesia é a palavra, o artista burila suas questões com o propósito de inaugurar e renovar o sentido do homem no mundo. Como a mitologia, cuja essência advém da oralidade, do narrar e recontar, a escrita literária cria polissemias e, assim sendo, escrever torna-se sinônimo de imaginação e (re)criação, uma vez que o ato de imaginar não implica meramente um estado, mas sim a existência humana em sua essência.

Soma-se a isso a presença da paródia que, como artefato da metaficção historiográfica, revela o indizível contido nas entrelinhas do discurso. Ao trazer para o presente antigos embates que se apresentam maniqueisticamente em seu país, a escritora abre o leque de possibilidades do que pode ser o bem e o mal, representados por Clemente e Davi, mostrando-nos que no seio da família e da nação as escolhas não podem ser pensadas individualmente, devendo, sempre ser relativizadas e ampliadas. Alegoricamente, portanto, pai e filho, Deus e diabo, sagrado e profano, antigo e novo, pré e pós-colonial são representações de um tempo a ser vivido, de opções a serem feitas.

Através da ironia, o elemento parodístico de que Paulina Chiziane lança mão para questionar tais ambivalências e dicotomias, é possível constatar como uma voz que expressa um ponto de vista insustentável pode diferir da do enunciador por subverter o que é e o que não é assumido por este. Por isso, a enunciação assume palavras, mas não necessariamente o ponto de vista do que elas representam no contexto, tornando-se, portanto, portadora de novos sentidos através da polifonia inerente ao romance como gênero literário. 
Ademais, a ironia é um tropo inerentemente dialético que sanciona a afirmação ambígua e ambivalente da realidade retratada, ao representar um uso consciente da metáfora e suas variações. Sendo assim, para que o fenômeno irônico se realize, torna-se necessária a decodificação dupla: uma de ordem linguística e outra de natureza discursiva que fazem, por sua vez, com que o leitor atue como co-produtor de significação do texto, instaurando-se como interlocutor.

Semelhante concepção é partilhada por Beth Brait ao afirmar que o percurso em direção à verdade é feito pela contramão, mas que o locutor conta com a sintonia do seu interlocutor. Ou seja: é de fato, no espírito do destinatário que a verdade irônica faz eclodir seu efeito, mas de maneira a estabelecer uma sequência de três elementos: o eu consciente, o outro e o eu inconsciente. (BRAIT, 1996, p. 165)

Também Mueck ressalta esta perspectiva ao apresentar a ironia do ponto de vista social que se aproxima dos princípios pedagógicos subjacentes ao romance:

A ironia tem basicamente uma função corretiva. É como um giroscópio que mantém a vida num curso equilibrado ou reto, restaurando o equilíbrio quando a vida está sendo levada muito a sério ou, como mostram algumas tragédias, não está sendo levada a sério o bastante, estabilizando o instável, mas também desestabilizando o excessivamente estável. (MUECKE, 1995, p. 19)

Ao questionar deliberadamente estes tênues limites, O Sétimo juramento permite o fugaz consolo que nos projeta para um momento improvável e perdido num futuro incerto que pode vir a ser alterado por uma maior percepção do presente. Pode também, em outro nível e servindo como elemento atenuante, expor também o outro e não apenas o eu.

Enfim, ao valer-se da "geografia mágica do país" (CHIZIANE, 2000, p. 146), de suas lendas, mitos e acontecimentos fantásticos, o romance atualiza aspectos etnográficos de Moçambique que atuam como catálises da lógica dos eventos e da dimensão psicológica de Davi, bem como de algumas personagens aparentemente secundárias como Lourenço, o amigo confidente, e a avó que, como representante de um saber ancestral, contribui positivamente para o desatamento destes vários nós.

Porém, para além das referências estritas a Moçambique, O Sétimo juramento pode ser lido também como rasura dos sinais de reconhecimento nacional e de um universo em que o poder gera um sistema de benesses cujos beneficiários têm que pagar um preço, pois "toda a realização humana exige suor e sacrifício. Toda a fortuna vem das mãos sujas. (...) Viver à larga sem o menor esforço é conversa fiada, porque tudo na vida tem o seu preço" (CHIZIANE, 2000, p. 150). 
Em suma, Paulina Chiziane une sua letra à de outros escritores africanos ao escrever sobre a condição humana a partir da perspectiva de seu país e de seu continente. Ao interrogar a História e a própria condição pós-colonial, ela rejeita o projeto de uma burguesia nacional pós-colonial, optando por um compromisso com uma causa maior: o dissabor africano, que não deixa de implicar o destino do homem. Mais que isso, indaga o próprio papel da literatura e da arte.

\section{REFERÊNCIAS BIBLIOGRÁFICAS}

BRAIT, Beth. A Ironia em perspectiva polifônica. Campinas: Unicamp, 1995.

CHIAMPI, Irlemar. O Realismo maravilhoso. São Paulo: Perspectiva, 1980.

CHIZIANE, Paulina. O sétimo juramento. Lisboa: Caminho, 2000.

DUTRA, Robson. O Insólito na literatura moçambicana e a afirmação de suas diferenças. In: GARCIA, Flávio; MICHELLI, Regina; PINTO, Marcelo. Reflexões sobre o Insólito na narrativa ficcional: o insólito na literatura e no cinema. Rio de Janeiro: Dialogarts, 2008.

FERRO, Marc. História das colonizações: das conquistas às independências - séculos XIII a XX. São Paulo: Companhia das Letras, 1996.

MUECKE, D. C. A ironia e o irônico. São Paulo: Perspectiva, 1995.

TODOROV, Tzvetan. Introdução à literatura fantástica. São Paulo: Perspectiva, 1980. . Memória do mal, tentação do bem. São Paulo: ARX, 2002.

WILLIAMS, Raymond. Marxismo e literatura. Rio de Janeiro: Jorge Zahar, 1987.

(Recebido para publicação em 29/11/2011, Aprovado em 08/01/2012) 